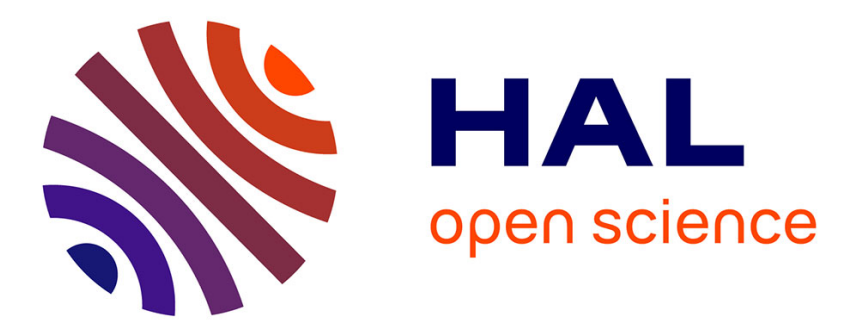

\title{
Use of laser spot thermography for the non-destructive imaging of thermal fatigue microcracking of a coated ceramic matrix composite
}

\author{
Thibaut Archer, Pierre Beauchêne, Bruno Passilly, Jean-Michel Roche
}

\section{- To cite this version:}

Thibaut Archer, Pierre Beauchêne, Bruno Passilly, Jean-Michel Roche. Use of laser spot thermography for the non-destructive imaging of thermal fatigue microcracking of a coated ceramic matrix composite. Quantitative InfraRed Thermography Journal, In press，10.1080/17686733.2019.1705732 . hal-02486633

\section{HAL Id: hal-02486633 \\ https://hal.science/hal-02486633}

Submitted on 21 Feb 2020

HAL is a multi-disciplinary open access archive for the deposit and dissemination of scientific research documents, whether they are published or not. The documents may come from teaching and research institutions in France or abroad, or from public or private research centers.
L'archive ouverte pluridisciplinaire HAL, est destinée au dépôt et à la diffusion de documents scientifiques de niveau recherche, publiés ou non, émanant des établissements d'enseignement et de recherche français ou étrangers, des laboratoires publics ou privés. 


\title{
Use of laser spot thermography for the non- destructive imaging of thermal fatigue microcracking of a coated ceramic matrix composite
}

\author{
Thibaut ARCHER ${ }^{\text {abc }}$, Pierre BEAUCHÊNEa, Bruno PASSILLYa, \\ Jean-Michel ROCHEa \\ aONERA, 29 avenue de la Division Leclerc, 92320 Châtillon, France \\ bSAFRAN Ceramics, a technology platform of Safran Tech, Mérignac, France \\ 'LMT (ENS Paris-Saclay / CNRS / Université Paris-Saclay), 61 avenue du \\ Président Wilson, 94235 Cachan, France
}

\begin{abstract}
In this paper, an environmental barrier coating (EBC), which has undergone thermal cycling under spatiotemporal gradients, is inspected using active thermography. The technique considered herein is known as laser spot thermography. This study deals with the detection of a very thin crack network of unknown orientation. A numerical analysis is presented to investigate the sensitivity of experimental parameters on the detection. Image processing using a Laplacian operator combined with histogram equalization to mitigate optical defects is then proposed to construct a cartography that is similar to scanning electron microscopy (SEM) observations despite the very adverse conditions.
\end{abstract}

Keywords: Laser spot thermography, crack network imaging, nondestructive evaluation 


\section{Introduction}

Over the past few years, many non-destructive evaluation (NDE) techniques, including those using thermography [1]-[4], have been successfully developed to assess the reliability of materials and structures. Among these thermal approaches, pulsed or transient thermography is the most commonly used, particularly on composite material [5], [6]. An approximately uniform and transient heat flow traverses the material through its thickness, enabling for detection of defects like delamination thanks to an infrared (IR) detector or camera. Defects such as surface cracks, which cannot be detected by this technique, are visible when the heat source is localised because of in-plane thermal diffusion. Optical defects, like scratches, induce a variation in the thermal footprint of the sample because of change in optical properties while cracks induce a variation because of local heat conductivity changes. This paper deals with the inspection and imaging of microscale crack networks using laser spot thermography (LST).

LST was first suggested by Kubiak [7] who proposed an experiment in which the heating is made by the absorption of light and the response recorded by a single IR detector. The author referred it as "photothermal radiometry". The IR detector monitors the thermal response at a fixed distance from the laser spot, which is moved along the sample for inspection. A defect between two points induces a variation from a reference response that enables its detection. If spot heating with a laser beam [8]-[13], ion or electron beam [14], [15] was widely studied, so was line heating [13], [16]-[18]. To optimise the detection and making it efficient in operating conditions, analytical works were then proposed to establish the sensitivity of the IR device to optical property changes (absorptivity or emissivity), surface roughness or cracks perpendicular to the scanning direction [19], [20]. 
More recently, IR cameras have been used to get a spatial response of the inspected material [21]-[23], leading to the name of thermography. One advantage of IR cameras is the larger detection area and the spatial resolution due to the small size of each element in the array of detectors. Besides, compared to single detectors, IR cameras allow for a much shorter scanning time to image a surface with a high resolution. To enhance the crack signatures, various methods have been proposed such as first and second order spatial derivatives [13], [21], normalisation by forward/backward scanning difference [23] or use of principle component analyses [24]. It is worth noting that pulsed laser spot [25], [26] and lock-in [27], [28] thermography have also been studied.

In most applications of LST or laser line thermography (LLT), the crack orientation is constant and the scanning direction is nearly perpendicular to it. In this study, the tested sample is a coated ceramic matrix composite (CMC), which has been cycled under laser heat flux conditions at high temperature. At the end of the test, a crack network has developed with no specific orientation and very thin openings, which is a substantial additional difficulty in terms of non-destructive imaging. Since LLT is not sensitive to cracks oriented along the scanning direction because of the absence of heat diffusion in the lateral direction, it was chosen to use the LST technique. The aim of the present study is to highlight the relevance of one-direction LST scanning for imaging a randomly oriented crack network with similar results when compared to the reference observation provided by Scanning Electron Microscopy (SEM).

The paper is organised as follows. Section 2 introduces the tested material and experimental methods used in this study. A 2D numerical model is then presented in Section 3 to assess the sensitivity of the thermal spot to cracks along the scanning direction. Data processing strategy and cartography reconstruction are detailed in Section 4. Last, the experimental results of LST are compared to SEM observations (Section 5) and discussed (Section 6). 


\subsection{Nomenclature}

$\alpha$ thermal diffusivity $\mathrm{m}^{2} . \mathrm{s}^{-1}$

$c$ specific heat $\mathrm{J} \cdot \mathrm{kg}^{-1} \cdot \mathrm{K}^{-1}$

$e$ crack opening in $\mathrm{mm}$

$k$ thermal conductivity $\mathrm{W} \cdot \mathrm{m}^{-1} \cdot \mathrm{K}^{-1}$

$P_{0}$ laser beam power $\mathrm{W}$

$r_{s}$ laser beam radius at $1 / \mathrm{e}^{2}$ from the source $\mathrm{m}$

$t$ time $\mathbf{s}$

$x, y, z$ spatial coordinates in $\mathrm{mm}$

$T$ temperature $\mathrm{K}$

$V$ speed of scanning $\mathrm{m} \cdot \mathrm{s}^{-1}$

$\rho$ mass density $\mathrm{kg} \cdot \mathrm{m}^{-3}$

$\varphi$ laser power in $\mathrm{W} / \mathrm{m}^{2}$

$P e=\frac{V r_{s}}{\alpha}$ Péclet dimensionless number

\section{Tested material and experimental methods}

\subsection{Environmental barrier coated ceramic matrix composite}

Due to their low density and good thermomechanical properties, $\mathrm{CMC}$ materials are currently under development for turbine engine applications [29]. Stability of CMCs in water vapor rich environments [30], [31] requires the development of new environmental barrier coatings (EBCs). Through-thickness cracks, which can initiate and propagate under thermal gradients [32], can have a critical effect on the lifetime of the system [33].

The tested sample consists of a woven CMC manufactured with Hi-Nicalon $\mathrm{S}-\mathrm{SiC}$ fibres and $\mathrm{SiC}$ matrix, the length and width of the sample are $20 \mathrm{~mm}$. The substrate is then coated with a thin layer of $(\mathrm{Si})$ bond coat, and finally with an environmental and thermal barrier coating made of rare earth silicate processed 
by Air Plasma Spray (APS). It has been cycled by a $\mathrm{CO}_{2}$ laser under thermal gradients with a maximum temperature around $1300^{\circ} \mathrm{C}$ and a surface thermal gradient (figure 1(a)). The laser beam heats the sample during 300s then stops for 300s (cooling phase). Under such conditions, creep of the coating is expected, leading to cracking during the cooling phase [34]. After 100 cycles, the resulting cracks are not visible to the naked eye (figure 1 (b)) but can be identified on SEM observations. These observations are considered as the reference method for the validation of the LST characterisation.

\subsection{Flying spot set-up}

The experimental setup (figure 2(a)) consists of an $\mathrm{Ar}^{+}$laser (1.5 $\mathrm{\mu m}$ wavelength, $3 \mathrm{~W}$ continuous wave output power) that locally heats the sample. The laser spot radius at $1 / \mathrm{e}^{2}$ is about $1.1 \mathrm{~mm}$. The IR observation is made by a FLIR X6580sC camera (sensitivity in the 3-5 $\mu \mathrm{m}$ wavelength range, $640 \times 512$ pixel definition, $15 \mu \mathrm{m} /$ pixel resolution, $20 \mathrm{mK}$ noise equivalent differential temperature). To study the influence of the spot size, a convergent lens is tested. Given the configuration, the laser beam and the IR camera are both fixed in the same reference frame and it is the sample that is put into motion. The sample surface is scanned in parallel lines as shown in figure 2(b) to cover an area of $15 \times 15 \mathrm{~mm}^{2}$. Several scanning speeds, laser spot sizes and scanning steps are investigated. The results will be presented in Section 5 .

\subsection{SEM observation}

The SEM observations are carried out for two different scales. The first one is the size of the crack opening which is around $1 \mu \mathrm{m}$ as shown in figure 3(a). The second one is the size of the crack network (figure 3(c)), which is several millimeters, and is provided for better global visibility. The crack network is reconstructed with several small $(1.16 \mathrm{~mm} \times 1.16 \mathrm{~mm})$ backscattered electron 
images of a 1500 x 1500 pixel definition as illustrated in figure 3(b) using a stitching process available on ImageJ. It is worth noting that the resolution of the images used for the cartography (figure 3(b) and figure $3(\mathrm{c})$ ) is 0.77 $\mu \mathrm{m} /$ pixel, which is much lower than the resolution of the IR camera. With the same resolution as the IR camera, cracks are not visible with SEM observations. The crack network is highlighted in figure 3(c) because it would require a huge image to see it at this magnification. Results show that, because of surface thermal gradient, a microcrack network grows around the center of the heated zone, with no specific orientation in the scanned Cartesian system. Besides, black spots are visible because of silicon carbide $(\mathrm{SiC})$ powders, which were used as speckle pattern for monitoring the thermal fatigue tests via digital image correlation, thus bonded to the EBC.

\section{2D finite element modelling}

The objective of this study is not to quantitatively compare a model/simulation to the experimental inspections [35] but only to understand the influence of experimental parameters such as scanning speed and laser beam size on the detection of a specific crack. Because analytical results with cracks are hardly available, particularly for random orientations and locations (or nonconstant crack depth/opening), a finite element model with COMSOL Multiphysics is used. The temperature rise caused by a laser spot source in a homogeneous (in absorptivity, emissivity and conductivity), non-transparent, isotropic material has been studied when considering a laser spot and an IR detector [19]. The authors have shown the sensitivity of the maximum signal acquired by the IR detector to the Péclet number which represents the ratio of convective heat transfer by conductive heat transfer. This dimensionless number will be used in this section for a crack oriented along the scanning direction, which is assumed to be the worst condition for detection by LST. 
The heat equation, without heat source, used to solve this problem reads

$$
k\left(\frac{\partial^{2} T}{\partial x^{2}}+\frac{\partial^{2} T}{\partial y^{2}}+\frac{\partial^{2} T}{\partial z^{2}}\right)=\rho c \frac{\partial T}{\partial t}
$$

To only calculate the step where the laser is located at the center of the sample, Eq. (1) becomes in case of constant speed V

$$
\left(\frac{\partial^{2} T}{\partial x^{2}}+\frac{\partial^{2} T}{\partial y^{2}}+\frac{\partial^{2} T}{\partial z^{2}}\right)=\frac{V}{\alpha} \frac{\partial T}{\partial x}
$$

Boundary conditions of the top surface heated by the laser spot are given by the power density

$$
\varphi=\frac{P_{0}}{\pi r_{s}^{2}} * e^{\frac{-\left((x-v t)^{2}+y^{2}\right)}{r_{s}^{2}}}
$$

The laser heats the center of the sample as shown on figure 4(a). Given the low range of temperature, only heat exchange by convection is considered. The heat exchange coefficient is equal to $10 \mathrm{~W} \cdot \mathrm{m}^{-2} \cdot \mathrm{K}^{-1}$ and the emissivity is equal to 0.8 . Losses by conduction are considered through the thickness of the sample and lateral surfaces are chosen to be adiabatic. A fixed crack geometry is studied with a length of $1 \mathrm{~mm}$, an opening of $1 \mu \mathrm{m}$ and a depth equal to that of the EBC. The thermal resistance is equal to $R_{t h}=e / k_{\text {air }}$ with $e$ the opening and $k_{\text {air }}$ the thermal conductivity of air. Table 1 shows the material properties used for the air gap and the EBC.

An example of a computed temperature field, when the laser is in the middle of the sample in the $X$ and $Y$ directions, is shown in figure 4(a). An asymmetrical temperature field in the $X$ (i.e. scanning) direction is observed because of the laser speed. A zoom on the center area (figure 4(b)) shows the crack along the scanning direction and the temperature profile which will be studied. This profile goes from the maximum temperature to the sample edge passing through the center of the crack. It is worth noting that for high speed (i.e. high Péclet number), the maximum temperature can be significantly shifted from the center of the laser spot [19]. In figure 4(c), the temperature profile reveals the presence and the location of the crack because of change in the 
induced thermal gradient. For the following results, the gap between the two sides of the crack is studied, as a function of the crack distance from the center, the scanning speed and the laser beam size.

\subsection{Influence of the laser spot size}

Analytical results give the temperature rise caused by laser heating with no crack or perturbation [9]. When normalizing each temperature profile by its maximum temperature, the higher the radius of the laser beam (i.e. the higher the Péclet number), the larger the detection area. However lower gradients for a larger laser beam size induce a lower quality of crack detection in this area. These results are confirmed in figure 5 in which the gap is plotted as a function of the crack distance for several Péclet numbers at a fixed scanning speed of $2 \mathrm{~mm} / \mathrm{s}$ (speed in the middle of the range of values accessible with the used translation stage). To detect thinner cracks, a small laser beam will be necessary even if it implies more scanning lines. Conversely, for larger defects, a bigger laser beam is permitted but more importantly faster scanning.

\subsection{Influence of the scanning speed}

The laser beam is not an experimental parameter easy to adjust, hence the study of the influence of the scanning speed on crack detection. In figure 6, temperature profiles are plotted for several scanning speeds for $r_{s}=5 * 10^{-4} \mathrm{~m}$ (close to the size of the laser beam used in the experimental set-up). For figure $6(\mathrm{a})$, each temperature profile is normalised by its maximum temperature, meaning a non-constant power density, whereas for figure 6(b), the normalisation is made by the maximum temperature of the lowest Péclet number. Unlike the previous influence study, for the same maximum temperature, a higher Péclet number induces a smaller detection area but larger thermal gradients. The choice 
of controlled parameters is crucial because it can be seen that a constant power density is likely to imply much better results with a lower Péclet number.

The change of the gap with the crack distance is plotted again in figure 7 . For a constant maximum temperature (figure 7(a)), a high Péclet will allow for an easier detection of cracks because of the higher thermal gradient. It is worth noting that the power required can be significantly high for the highest Péclet number. As illustrated in figure $7(\mathrm{~b})$, for a constant power density, a slow scanning speed is desirable because the maximum temperature is higher. Last, in both cases and regardeless of the Péclet number, there is an optimal distance at which the gap is maximum. This distance corresponds to the maximum gradient of the temperature profiles plotted in figure 6 as confirmed in figure 8.

This model confirms the sensitivity of LST to cracks, even when they are oriented along the scanning direction. It mostly enables the influence of the scanning speed and of the laser beam size to be evaluated for the detectability of the cracks: for a given constant maximum temperature, a high scanning speed induces a better detection in a smaller area whereas for a given constant power density, which is more conventional, a low scanning speed induces a better detection in a larger area. Moreover, it opens the possibility of detecting randomly oriented cracks with a one-direction scanning LST experiment. The reconstruction of a whole crack network could be carried out more easily and much faster than with two directions of scanning.

From an experimental point of view, it appears that it is much more complex to keep the maximum temperature constant since it would require large powers, at fixed $r_{s}$, for high speeds, which is not feasible for this configuration. Therefore, the choice is made to carry out LST tests with a constant power density. As for the size of the laser beam, which is not easily controlled either, its influence on the detection of microcracks can be indirectly taken into account by the one of the scanning speed through the Péclet number. 


\section{Crack network reconstruction algorithm}

\subsection{Crack detection method}

The difficulty to separate cracks from optical defects or large roughness justifies the application of a specific data processing tool of the raw LST images. The physical mechanism for crack detection comes directly from Fourier's law

$$
\dot{\boldsymbol{q}}=-k \boldsymbol{\nabla} T=-\frac{1}{R_{t h}} \boldsymbol{\nabla} T
$$

with $\dot{\boldsymbol{q}}$ the heat flux density in $W / m^{2}, \boldsymbol{\nabla} T$ the thermal gradient in $K \cdot m^{-1}$ and $R_{t h}$ the thermal resistivity in $W^{-1} . m$. K. It shows that, as recalled in Section 3, a crack induces a lower thermal conductivity (i.e. a higher thermal resistivity) that results in a change in the thermal gradient, hence the use of derivative methods.

Derivative images of one given crack using finite differences are shown in figure 9 . The crack has an opening of about $1 \mu \mathrm{m}$ and is particularly interesting because of its bifurcation. Figures $9(\mathrm{a})$ and 9(b) display the first-derivatives, respectively in the $X$ and $Y$ directions. The sensitivity to a crack perpendicular to the scanning direction is better for the same distance from the center of the laser beam. As for the crack oriented along the scanning direction, it can still be monitored but it is more affected by the laser residual signature. Figures 9(c) and $9(\mathrm{~d})$ are the sum of normalised absolute first-order derivatives and secondorder derivatives (i.e. Laplacian operator). Although the signal-to-noise ratio is slightly better for the first- order derivative, the laser signature is also more visible, which can make the interpretation more difficult. Besides, the secondorder derivative sensitivity has the advantage of being less dependent on the crack direction. For these reasons, the Laplacian operator of the image is used for the reconstruction in the next subsection. 


\subsection{Reconstruction of an optimised thermal map}

Since the laser beam and the IR camera are fixed and the sample is in motion, the data must first be stored in a global reference frame to construct a complete map of the sample as shown in figure 10(a). For a given scanning speed, the displacement of the sample and the start of the IR acquisition (at a fixed frequency) must be synchronised to ensure a constant time step between two consecutive images. The final image is reconstructed from the mean of each value at a single position in the global frame. Last, the IR framerate is adjusted, depending on the scanning speed, to keep the same number of independent pixel between two consecutive images: 8 pixels in this study.

As seen in figure 10(b), laser heating only represents a small part of the acquired IR frame. The application of the Laplacian operator on the entire image to construct the map would result in masking the signature of a crack since it affects only a few pixels. Therefore, the Laplacian operator is applied on a specific part of the IR image, symmetric with respect to the center of the heated area in the $Y$ direction and on the half part of the image that has not been heated yet in the $X$ direction (figure 10(b)). It is worth noting that the selection of this part strongly depends on the acquisition parameters: a high scanning speed will induce a smaller sensitivity for the detection in the $\mathrm{Y}$ direction (figure 6), which calls for the choice of a rectangular part. Conversely, for a slow scanning speed, the selected part should tend towards a square. In this study, as the maximum scanning is limited (see Table 2), the shape of the subpart analysed is kept constant with a size of 56 pixels in the $X$ (scanning) direction, meaning that one pixel is averaged by 7 thermograms. The size in the $Y$ direction is adjusted depending on the scanning step to ensure continuity between two consecutive lines. 


\subsection{Optical defect}

The signal acquired with the IR camera can be affected by optical defects such as scratches, changes of emissivity or absorptivity. In the present study, one has to deal with simultaneous changes of emissivity and absorptivity due to silicon carbide powders on the CMC sample. During the test, $\mathrm{SiC}$ powders are exposed to very high temperatures and some of them bond to the EBC. As already investigated in the literature [36], silicon carbides are known to have a very high emissivity whereas the emissivity of the tested EBC is very low at room temperature. The effects of these optical defects are seen in figure 11: even when the laplacian operator is applied, it turns out that the crack is totally overshadowed by the particles at the center of the map and can hardly be seen by naked eye.

To overcome this issue and improve the crack thermal signature, an additional image processing is applied after the Laplacian operator. Histogram equalization [37] is one possible method, adaptive histogram equalization [38] can also be used because the histogram is not strictly confined to a particular region even if the proportion of powder is very low. To avoid noise amplification, contrast limiting should also be applied. The benefits of this image processing approach, combined with the Laplacian operator, are illustrated in figure 11(c), which displays the contrast limited adaptive histogram equalization (CLAHE) final image.

\section{Results}

In order to confirm the influences studied in Section 3, several scans of the sample were made with various acquisition parameters, as summarised in Table 2. For technical reasons, the maximum scanning speed was set to $2.5 \mathrm{~mm} / \mathrm{s}$. In this study, two consecutive images are 8 pixels apart from each other. The spot 
size was changed using a converging lens. In each case, the integration time of the IR camera was selected to have the maximum number of digital levels in the image. For one spot size, the incoming energy is kept constant for various scanning speeds.

\subsection{Influence of laser spot size}

The construction is shown for cases 1 and 2 (see Table 2) in figure 12. It is observed that with the same scanning speed, a smaller laser spot seems to result in a better detection, especially in terms of contrast. It is also worth noting that the edges of the crack network (i.e. where the crack openings are close to 0) are more visible with the smallest laser beam, meaning that the detection threshold, in terms of crack opening and depth, is linked to the spot size. In figure 12(b), stripes, which are not visible with the largest laser beam, occur. They are caused by higher thermal gradients, even without crack, that induce signal after the Laplacian operator and also due to the poor signal-to-noise ratios. They cannot be easily removed with a Fourier transform of the image.

\subsection{Influence of the scanning speed}

As discussed in Section 3, the scanning speed is directly linked to the maximum temperature (i.e. the crack signature) through the Péclet number. For constant incident energy, for a given distance from the crack, the signal is always higher for a low speed. This result is confirmed in figure 13 in which digital level (DL) fields are plotted at the same position for cases 2, 3 and 4 (see Table 2). The maximum levels decrease by $2.5 \%$ between the first two speeds and by $8 \%$ between the second and the last one, confirming a nonlinear decrease with an increasing Péclet number. In figure 13(b), the gradient of a DL profile perpendicular to the scanning direction is plotted against the distance from the center (as in Section 3). Almost no difference can be seen between cases 2 and 3, 
whereas a small decrease in the gap (i.e. the contrast) starts for the highest speed.

\subsection{Comparison with SEM observations}

In figure 14, maps of the crack network using LST and SEM observations are shown. Although stripes do not ease visualisation, each crack visible by SEM observations is also seen on LST cartography despite the low crack opening and even if LST is more sensitive to optical defects such as powders.

Compared to SEM observations, LST is a much faster inspection technique. For SEM observations of this sample, it takes more than 2 hours to clean and prepare the surface, to set and acquire all the small images and finally to stitch them and highlight the crack network. For LST inspection, the setup preparation takes most of the time. The scan itself, for the configuration with the small laser spot and high scanning speed (case 4), only lasts around $2.5 \mathrm{~min}$ (the part needed to image the global crack network only corresponds to $20 \%$ of that duration); then the time for data processing and map reconstruction does not exceed $1 \mathrm{~min}$ with a standard computer. Another way to reduce the inspection time is to optimise the scanning step as shown in figure 15 in which the scanning step is twice the one of figure 12(b) The optimal value mainly depends on the scanning speed and the laser beam size.

Such short durations suggest the possibility of using LST as an in-situ evaluation technique. This could be done on tests that already include a laser beam (to heat a sample) or in mechanical tests for instance.

\section{Conclusions and perspectives}

This paper highlights the relevance of LST as a reliable NDE technique to detect cracks in very challenging conditions: (1) very small crack openings, (2) unknown and random orientations of the cracks and (3) large optical defects 
during the scan. Compared to SEM observations or dye penetrant inspection (DPI), the technique has the major advantage of being non-intrusive and does not require any preparation of the region of interest even if a clean surface is desirable to avoid variations of the thermal footprint for other reasons than microcracks. The gain in time is quite substantial.

The paper also deals with the detection and enhancement of the crack thermal signature and presents a simple but reliable image processing method to image a whole crack network by first considering the sum of second-order spatial derivatives, even if more sensitive to noise, to best filter the signature of the laser beam when highly focused, then by only considering a specific part of the IR image. In the latter case, the detection turns out to be more reliable. Besides, the sensitivity study shows the influences of parameters of acquisition and interactions between them through the Péclet number.

In this study, the first limitation to the scanning time was the translation stage speed whereas the IR camera can work at much higher rates. This type of upgrade would also imply a more powerful laser to work with a constant maximum temperature. It would also be interesting to see the influence of linear defects such as scratches on image processing because they have the same morphology as cracks contrary to powders. The experimental sensitivities to operating parameters to optimise the scanning time and the detection thresholds of crack depths and openings are also under investigation.

\section{Acknowledgements}

The authors would like to thank Dr. Jean-Claude Krapez and Dr. François Hild for their help and advice on this work, which was supported under PRC MECACOMP, French research project co-funded by DGAC and SAFRAN Group, managed by SAFRAN Group and involving SAFRAN Group, ONERA and CNRS. 


\section{References}

[1] W. J. Staszewski, C. Boller, et G. R. Tomlinson, Éd., Health Monitoring of Aerospace Structures. Chichester, UK: John Wiley \& Sons, Ltd, 2003.

[2] T. Stepinski, T. Uhl, et W. Staszewski, Advanced Structural Damage Detection: From Theory to Engineering Applications. Chichester, UK: John Wiley \& Sons, Ltd, 2013.

[3] D. Kalliopi K. Aligizaki, « Nondestructive Testing Overview, Volume 10 of the Nondestructive Testing Handbook», Anti-Corros. Methods Mater., vol. 50, no 4, 2003.

[4] W. N. Reynolds, "Thermographic methods applied to industrial materials », Can. J. Phys., vol. 64, no 9, p. 1150-1154, 1986.

[5] P. Cielo, "Pulsed photothermal evaluation of layered materials », J. Appl. Phys., vol. 56, no 1, p. 230-234, 1984.

[6] D. L. Balageas, « Defense and illustration of time-resolved pulsed thermography for NDE », Quant. InfraRed Thermogr. J., vol. 9, no 1, p. 3-32, 2012.

[7] E. J. Kubiak, "Infrared Detection of Fatigue Cracks and Other Near-Surface Defects », Appl. Opt., vol. 7, no 9, p. 1743, 1968.

[8] I. Kaufman, P.-T. Chang, H.-S. Hsu, W.-Y. Huang, et D.-Y. Shyong, "Photothermal radiometric detection and imaging of surface cracks", $J$. Nondestruct. Eval., vol. 6, no 2, p. 87-100, 1987.

[9] J.-C. Krapez et al., "La caméra photothermique (flying spot camera) », in Instrumentation Mesure Métrologie (I2M), vol. 1, n-2, p. 9-39, 2001.

[10] Y. Q. Wang, P. K. Kuo, L. D. Favro, et R. L. Thomas, "Flying Laser Spot thermal Wave IR Imaging of Horizontal and Vertical Cracks», in Review of Progress in Quantitative Nondestructive Evaluation, D. O. Thompson et D. E. Chimenti, Éd. Boston, MA: Springer US, 1990, p. 511-516.

[11] Y. Q. Wang, P. Chen, P. K. Kuo, L. D. Favro, et R. L. Thomas, « Flying Laser Spot Thermal Wave IR Imaging ", in Review of Progress in Quantitative Nondestructive Evaluation, D. O. Thompson et D. E. Chimenti, Éd. Boston, MA: Springer US, 1992, p. 453-456.

[12] A. Rashed, D. P. Almond, D. A. S. Rees, S. Burrows, et S. Dixon, « Crack Detection by Laser Spot Imaging Thermography », in AIP Conference Proceedings, Portland, Oregon (USA), 2007, vol. 894, p. 500-506.

[13] T. Li, D. P. Almond, et D. A. S. Rees, « Crack imaging by scanning laser-line thermography and laser-spot thermography », Meas. Sci. Technol., vol. 22, no 3, p. 035701, 2011.

[14] D. N. Rose, H. Turner, et K. O. Legg, "Ion-acoustic microscopy », Can. J. Phys., vol. 64, no 9, p. 1284-1286, 1986.

[15] E. Brandis et A. Rosencwaig, « Thermal-wave microscopy with electron beams », Appl. Phys. Lett., vol. 37, no 1, p. 98-100, 1980. 
[16] J. Varis, R. Lehtiniemi, J. Hartikainen, et J. Rantala, « Transportable infrared line scanner based equipment for thermal nondestructive testing ", Research in Nondestructive Evaluation, vol. 6, no 2, p. 85-97, 1995.

[17] J. Varis, J. Rantala, et J. Hartikainen, « An infrared line scanning technique for detecting delaminations in carbon fibre tubes », NDT E Int., vol. 29, no 6, p. 371-377, 1996.

[18] R. Lehtiniemi, J. Rantala, et J. Hartikainen, «A Photothermal Line-Scanning System for NDT of Plasma-Sprayed Coatings of Nuclear Power Plant Components », Res. Nondestruct. Eval., vol. 6, no 2, p. 99-123, 1995.

[19] J.-C. Krapez, «Résolution spatiale de la camera thermique source volante », Int. J. Therm. Sci., vol. 38, no 9, p. 769-779, oct. 1999.

[20] T. Maffren, F. Lepoutre, G. Deban, A. Mavel, et P. Juncar, «Influence of the surface roughness on images acquired by flying spot active thermography: Case of the high pressure turbine blades", in 2012 IEEE International Instrumentation and Measurement Technology Conference Proceedings, Graz, Austria, 2012, p. 454-457.

[21] J. Schlichting, M. Ziegler, C. Maierhofer, et M. Kreutzbruck, « Flying laser spot thermography for the fast detection of surface breaking cracks ", in 18th World Conference on Nondestructive Testing, Durban, 2012.

[22] U. Netzelmann, «Flying-spot lock-in thermography and its application to thickness measurement and crack detection », in Proceedings of the 2014 International Conference on Quantitative InfraRed Thermography, 2014.

[23] T. Maffren, «Détection et caractérisation de fissures dans des aubes de turbine monocristallines pour l'évaluation de leurs durées de vie résiduelles », $\mathrm{PhD}$ Thesis, Conservatoire national des arts et metiers-CNAM, 2013.

[24] S. Hermosilla-Lara, P. Y. Joubert, D. Placko, F. Lepoutre, et M. Piriou, «Enhancement of open-cracks detection using a principal component analysis/wavelet technique in photothermal nondestructive testing », in Proceedings of the 2002 International Conference on Quantitative InfraRed Thermography, 2002.

[25] T. Li, D. P. Almond, et D. A. S. Rees, « Crack imaging by scanning pulsed laser spot thermography », NDT E Int., vol. 44, no 2, p. 216-225, 2011.

[26] N. W. Pech-May, A. Oleaga, A. Mendioroz, et A. Salazar, « Fast Characterization of the Width of Vertical Cracks Using Pulsed Laser Spot Infrared Thermography », J. Nondestruct. Eval., vol. 35, no 2, p. 22, 2016.

[27] Y. Fedala, M. Streza, J.-P. Roger, G. Tessier, et C. Boué, « Open crack depth sizing by laser stimulated infrared lock-in thermography », J. Phys. Appl. Phys., vol. 47, no 46, p. 465501, 2014.

[28] J. González, A. Bedoya, A. Mendioroz, et A. Salazar, « Measuring the thermal resistance of vertical interfaces separating two different media using infrared thermography », Int. J. Therm. Sci., vol. 135, p. 410-416, 2019.

[29] J. A. DiCarlo, H.-M. Yun, G. N. Morscher, et R. T. Bhatt, « SiC/SiC Composites for $1200^{\circ} \mathrm{C}$ and Above », in Handbook of Ceramic Composites, N. P. Bansal, Éd. Springer US, 2005, p. 77-98. 
[30] E. J. Opila, J. L. Smialek, R. C. Robinson, D. S. Fox, et N. S. Jacobson, « SiC Recession Caused by $\mathrm{SiO} 2$ Scale Volatility under Combustion Conditions: II, Thermodynamics and Gaseous-Diffusion Model », J. Am. Ceram. Soc., vol. 82, no 7, p. 1826-1834, 1999.

[31] R. C. Robinson et J. L. Smialek, « $\mathrm{SiC}$ recession caused by $\mathrm{SiO} 2$ scale volatility under combustion conditions: I, experimental results and empirical model », $J$. Am. Ceram. Soc., vol. 82, no 7, p. 1817-1825, 1999.

[32] A. G. Evans et J. W. Hutchinson, "The mechanics of coating delamination in thermal gradients », Surf. Coat. Technol., vol. 201, no 18, p. 7905-7916, 2007.

[33] B. T. Richards, S. Sehr, F. de Franqueville, M. R. Begley, et H. N. G. Wadley, « Fracture mechanisms of ytterbium monosilicate environmental barrier coatings during cyclic thermal exposure », Acta Mater., vol. 103, p. 448-460, 2016.

[34] D. Zhu et R. A. Miller, « Determination of creep behavior of thermal barrier coatings under laser imposed high thermal and stress gradient conditions », $J$. Mater. Res., vol. 14, nº 01, p. 146-161, 1998.

[35] A. Thiam, J.-C. Kneip, E. Cicala, Y. Caulier, J.-M. Jouvard, et S. Mattei, « Modeling and optimization of open crack detection by flying spot thermography », NDT E Int., vol. 89, p. 67-73, 2017.

[36] G. Neuer et G. Jaroma-Weiland, "Spectral and Total Emissivity of HighTemperature Materials », Int. J. Thermophys., vol. 19, no 3, p. 917-929, 1998.

[37] A. K. Jain, Fundamentals of digital image processing. Englewood Cliffs, NJ: Prentice Hall, 1989.

[38] S. M. Pizer et al., «Adaptive Histogram Equalization and Its Variations », Comput. Vis. Graph. Image Process., vol. 39, no 3, p. 355-368, sept. 1987. 
TABLE 1: Material parameters for the simulation

\begin{tabular}{ccccc}
\hline Material & $\begin{array}{c}\rho \text { density } \\
\left(\mathrm{kg} . \mathrm{m}^{-3}\right)\end{array}$ & $\begin{array}{c}c \text { specific heat } \\
\left(\mathrm{J} . \mathrm{kg}^{-1} \cdot \mathrm{K}^{-1}\right)\end{array}$ & $\begin{array}{c}k \text { conductivity } \\
\left(\mathrm{W} . \mathrm{m}^{-1} \cdot \mathrm{K}^{-1}\right)\end{array}$ & $\begin{array}{c}\alpha \text { diffusivity } \\
\left(\mathrm{m}^{2} . \mathrm{s}^{-1}\right)\end{array}$ \\
\hline EBC & 3.68 & 500 & 4.4 & $2.4 * 10^{-6}$ \\
\hline Air & 1.205 & 1000 & 0.02 & $1.66 * 10^{-5}$ \\
\hline
\end{tabular}

TABLE 2: Parameters of acquisition for LST imaging

\begin{tabular}{cccccc}
\hline Case & $\begin{array}{c}\text { Scanning } \\
\text { speed } \\
(\mathrm{mm} / \mathrm{s})\end{array}$ & $\begin{array}{c}\text { IR } \\
\text { framerate } \\
(\mathrm{Hz})\end{array}$ & $\begin{array}{c}\text { Péclet } \\
\text { number }\end{array}$ & $\begin{array}{c}\text { Spot size } \\
\text { at } 1 / \mathrm{e}^{2} \\
(\mathrm{~mm})\end{array}$ & $\begin{array}{c}\Delta x \text { between } \\
2 \text { lines } \\
(\mathrm{mm})\end{array}$ \\
\hline 1 & 0.6 & 5 & 1.85 & 0.75 & 1.2 \\
\hline 2 & 0.6 & 5 & 1 & 0.4 & 0.8 \\
\hline 3 & 1.2 & 10 & 2 & 0.4 & 0.8 \\
\hline 4 & 2.4 & 20 & 4 & 0.4 & 0.8 \\
\hline
\end{tabular}




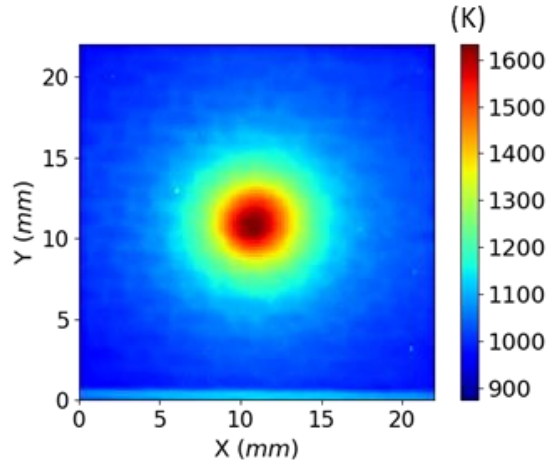

(a)

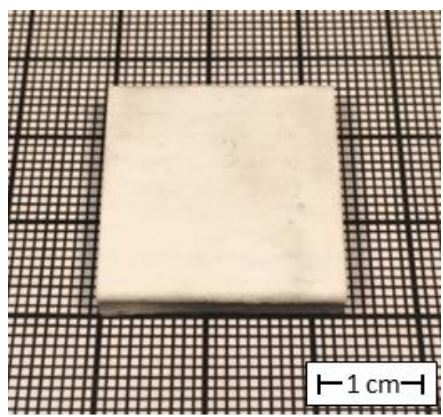

(b)

FIGURE 1 : (a) Temperature field (K) at a stabilised heat level during thermal cycling and (b) sample after the test with no visible damage

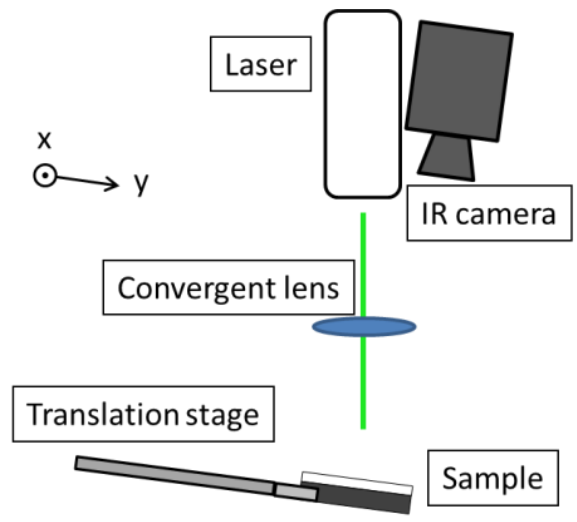

(a)

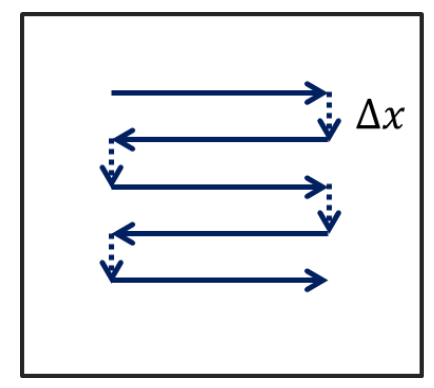

(b)

FIGURE 2 : (a) Experimental setup used for laser spot thermography and (b) path of inspection for a sample 


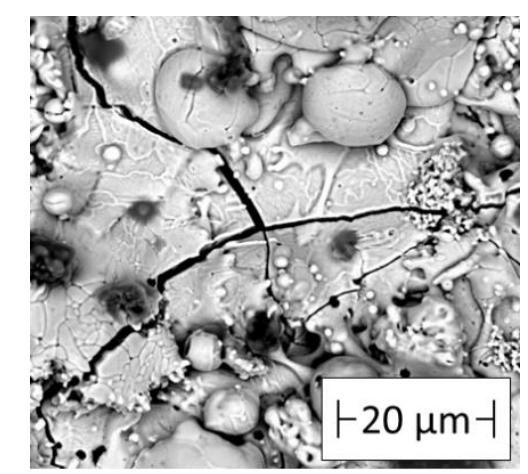

(a)

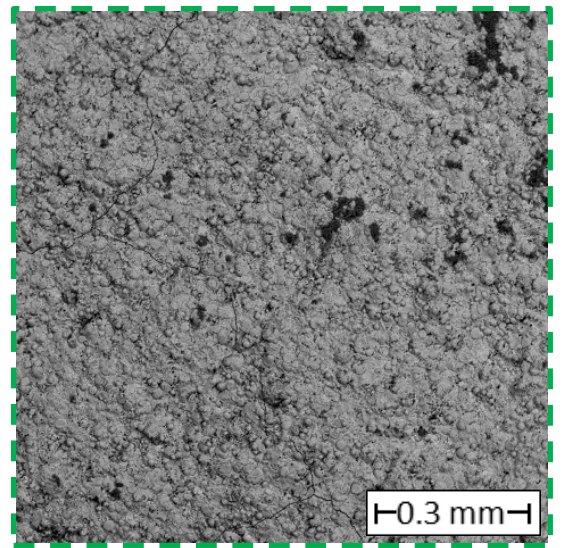

(b)

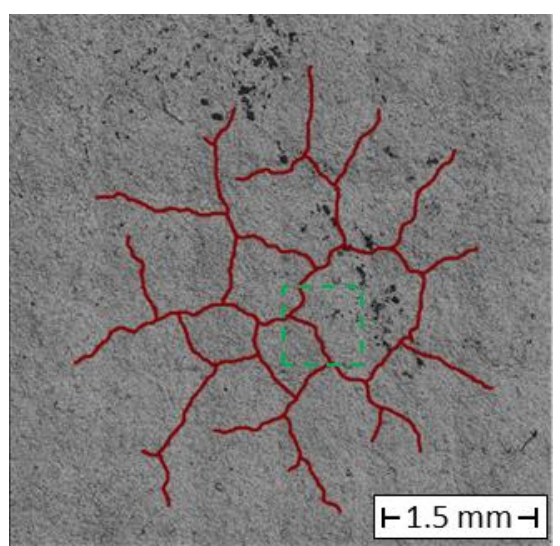

(c)

FIGURE 3: SEM observations of an EBC after thermal cycling with (a) high magnification showing a very thin crack with $\mathrm{SiC}$ powder (black spots), (b) a lower magnification of an image used for the cartography with cracks and (c) the cartography showing the hand drawn crack network 


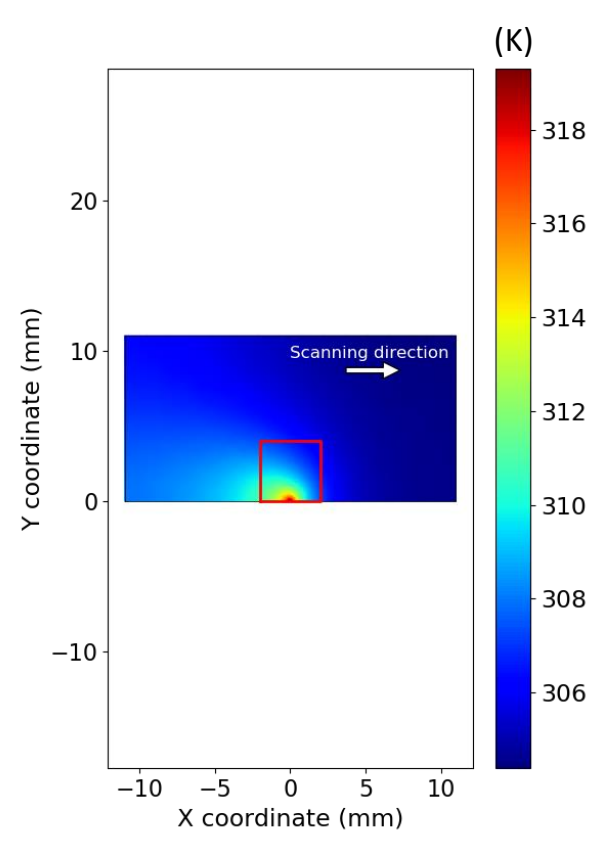

(a)

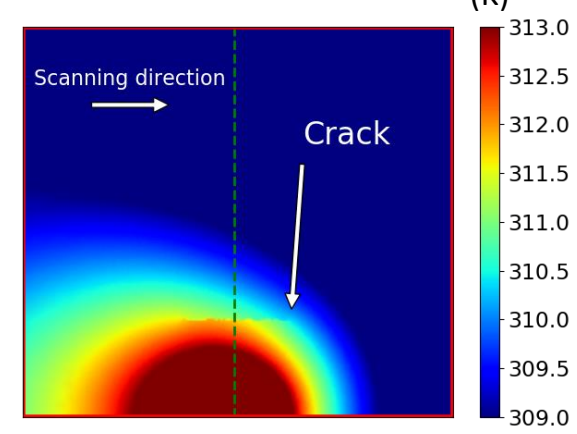

(b)

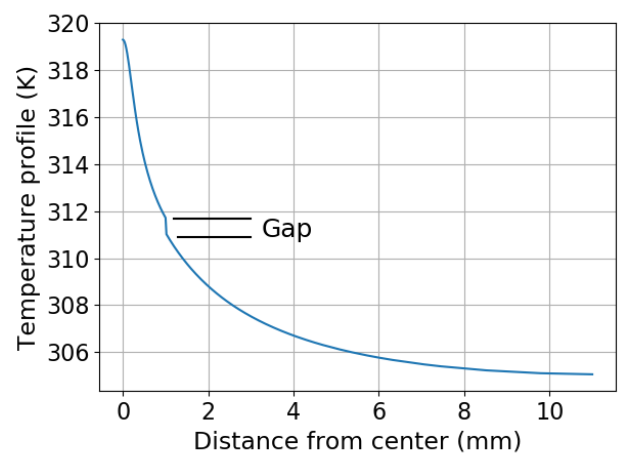

(c)

FIGURE 4: (a) Example of computed temperature field (K) with (b) a crack along the scanning direction (reduced temperature range) and (c) temperature profile perpendicular to the crack

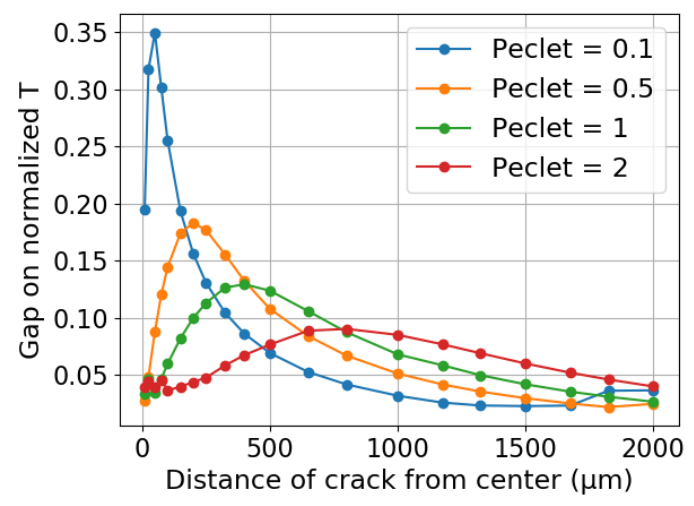

FIGURE 5: Influence of the laser beam size with a constant speed on the detection of a crack 


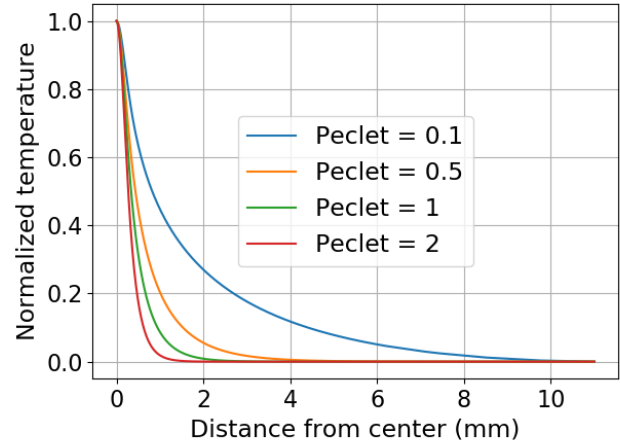

(a)

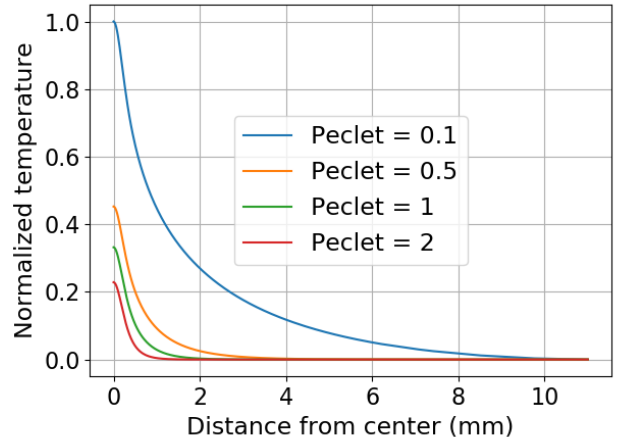

(b)

FIGURE 6: Influence of the scanning speed on the computed temperature profile at (a) fixed maximum temperature and (b) fixed power density

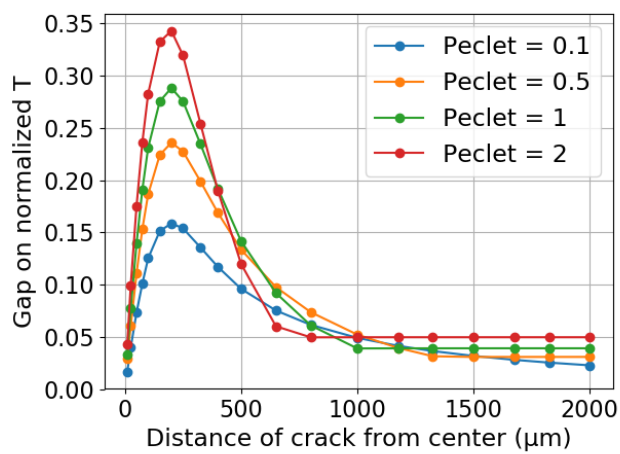

(a)

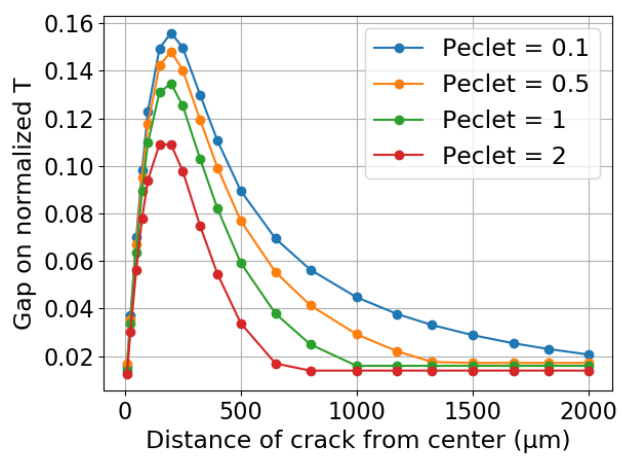

(b)

FIGURE 7: Influence of laser speed on the detection with (a) a constant maximum temperature and (b) a constant power density 


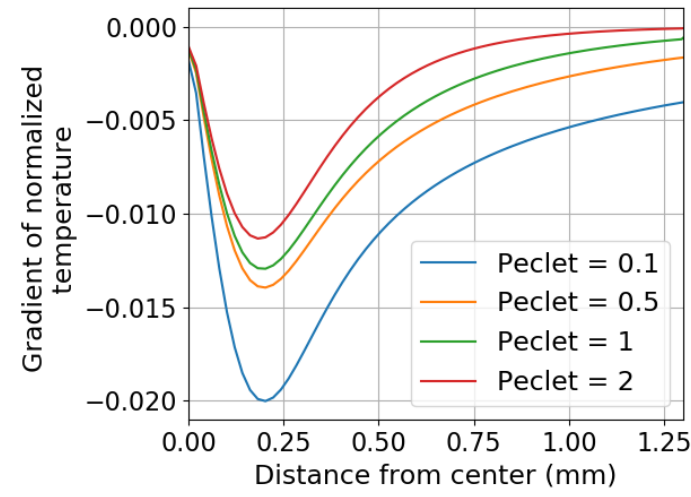

FIGURE 8: Gradient of temperature profiles in figure 6(b) showing the optimal distance

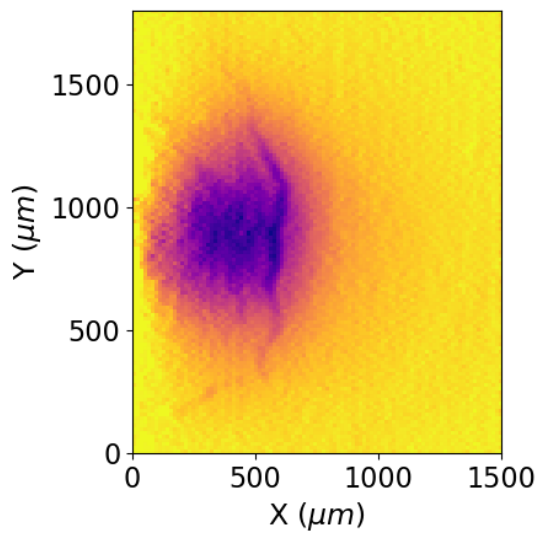

(a)

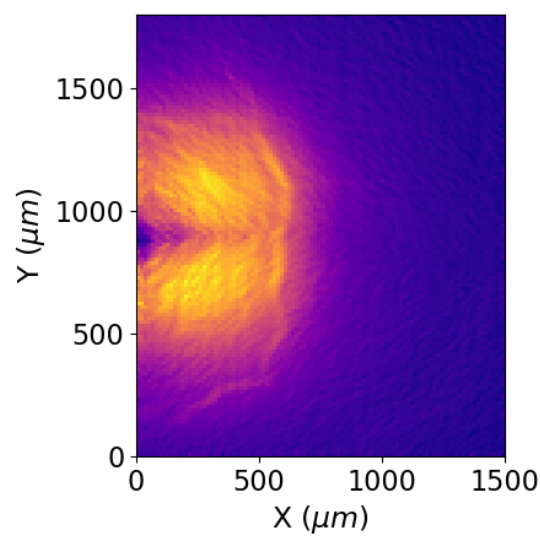

(c)

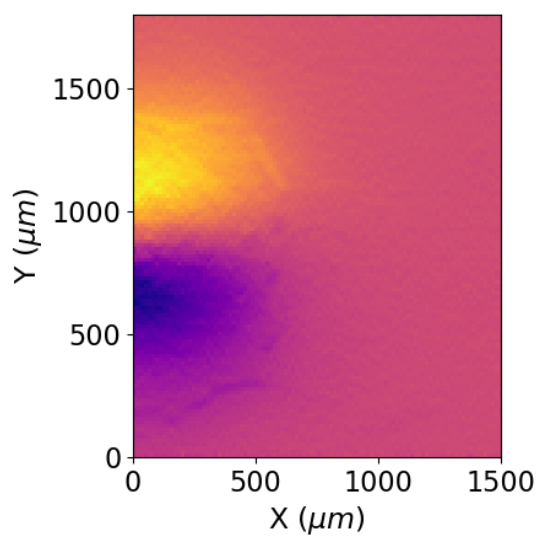

(b)

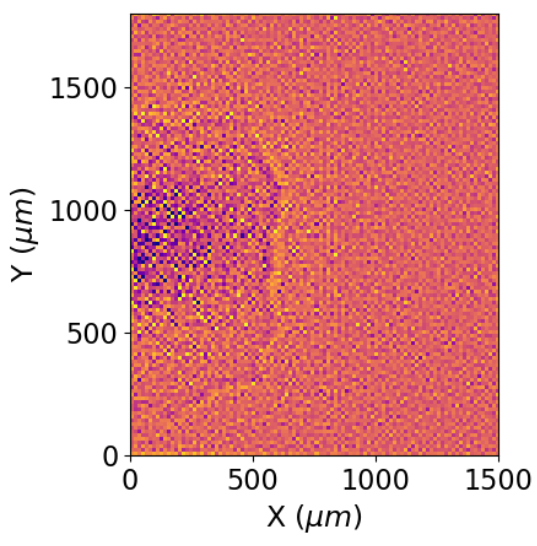

(d)

FiguRE 9: (a) First-order derivative in the $\mathrm{X}$ direction, (b) first-order derivative in the $\mathrm{Y}$ direction, (c) summed and normalised first-order derivative and (d) summed and normalised second-order derivative of the thermal image 


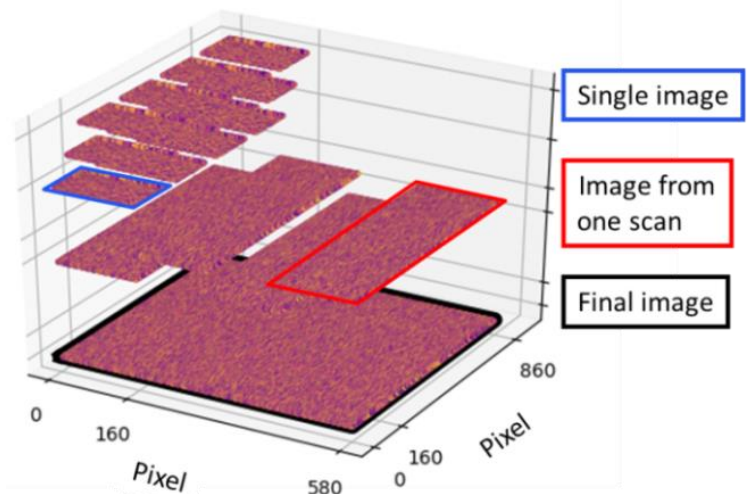

(a)

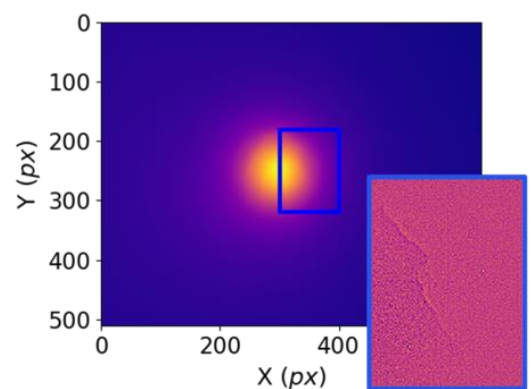

(b)

FIGURE 10: (a) Data processing to build the final thermal map and (b) raw data and Laplacian operator on the center area

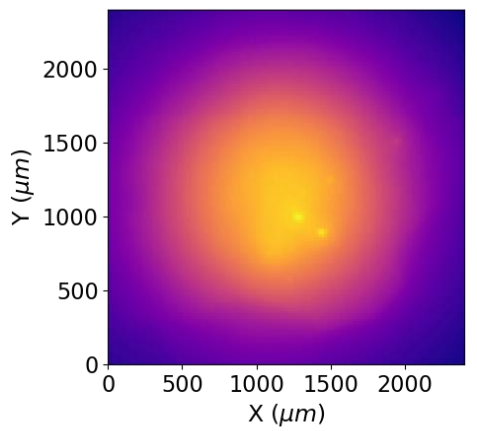

(a)

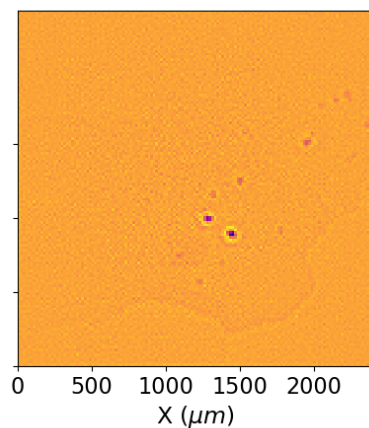

(b)

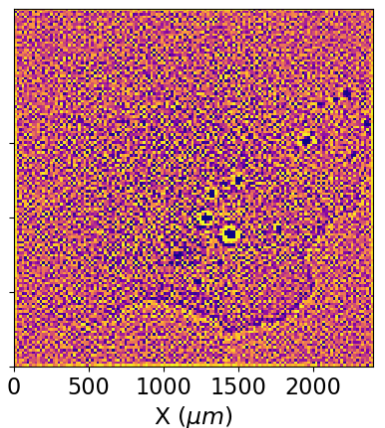

(c)

FIGURE 11 : Images of (a) raw data acquired during inspection, (b) Laplacian operator and (c) Laplacian operator corrected with a CLAHE filter 


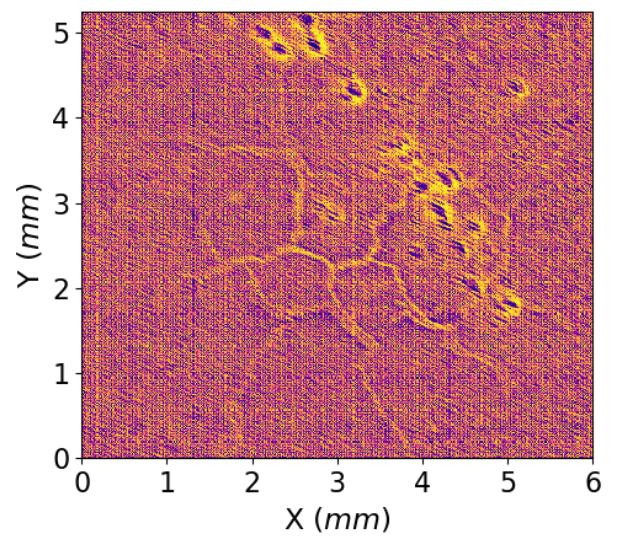

(a)

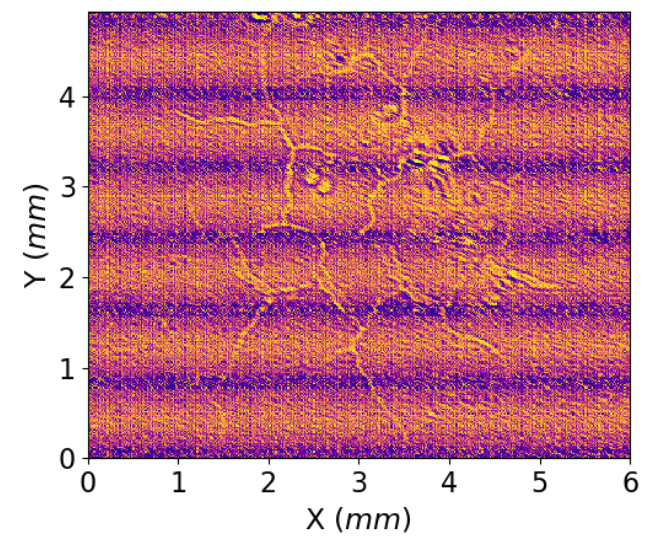

(b)

FIGURE 12 : Influence of the laser spot size on the thermal map reconstruction with (a) a natural and (b) a focused laser beam

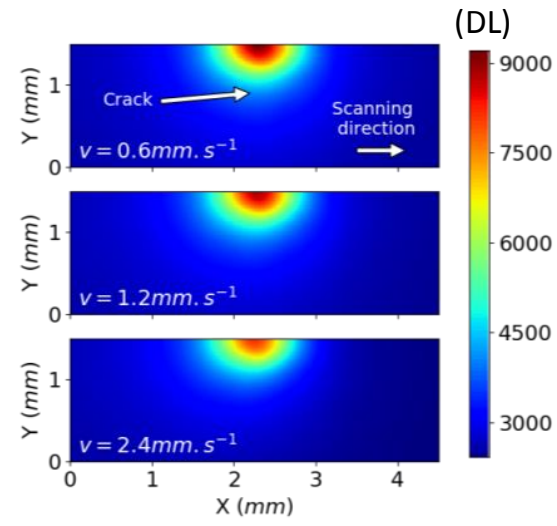

(a)

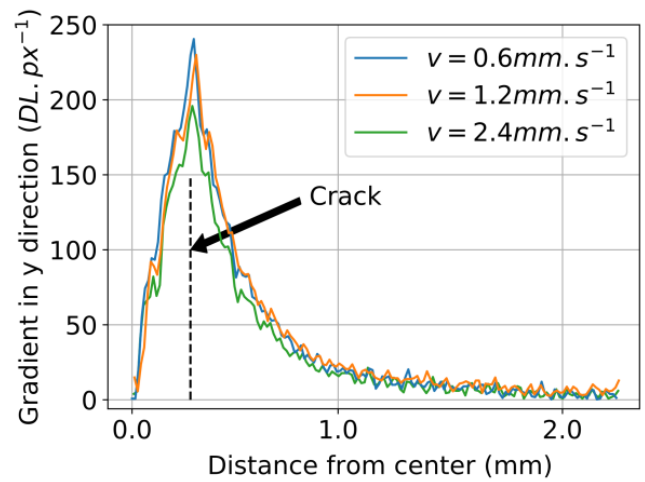

(b)

FigURE 13: Influence of the scanning speed on (a) thermal image (DL) at the same position and (b) associated thermal profiles disturbed by a crack 


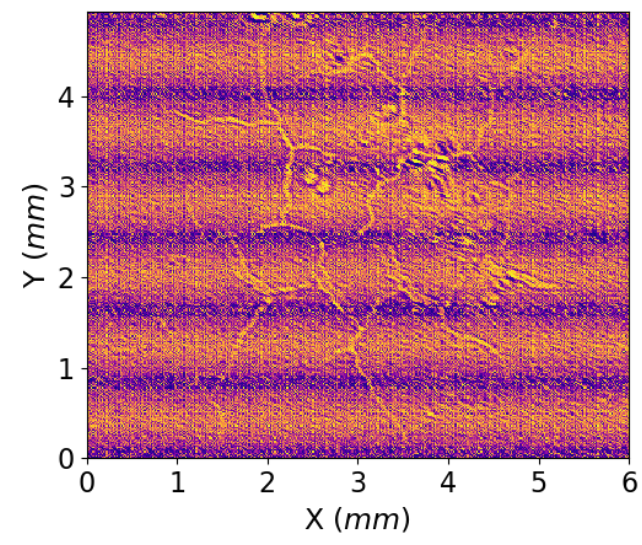

(a)

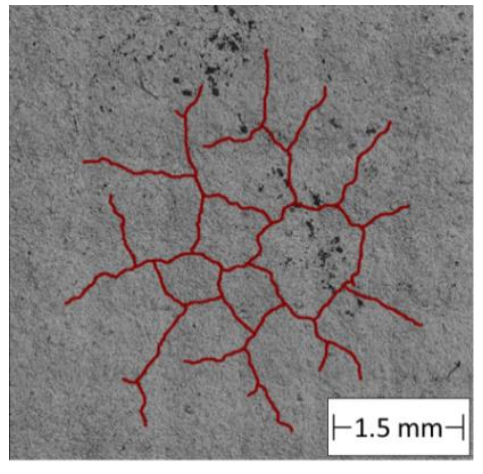

(b)

FIGURE 14: Imaging of the same crack network with (a) LST and (b) SEM observations

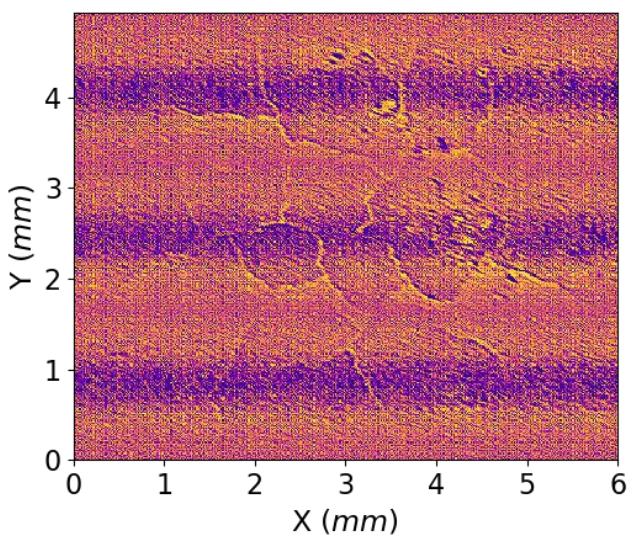

FIGURE 15: Influence of the scanning step on the reconstruction 